\title{
Self-Regulation in Children and Minors in Institutional Care
}

\author{
Karla Hrbackova ${ }^{1}$ \& Sona Vavrova ${ }^{2}$ \\ ${ }^{1}$ Department of Pedagogical Sciences, Faculty of Humanities, Tomas Bata University in Zlín, Czech Republic \\ ${ }^{2}$ Research Centre of Faculty of Humanities, Faculty of Humanities, Tomas Bata University in Zlín, Czech \\ Republic \\ Correspondence: Karla Hrbackova, Faculty of Humanities, Tomas Bata University in Zlín, 76001 Zlín, Czech \\ Republic. Tel: 420-576-037-439. E-mail: hrbackova@fhs.utb.cz
}

Received: December 17, 2014 Accepted: January 27, 2015 Online Published: April 28, 2015

doi:10.5539/ies.v8n5p139 URL: http://dx.doi.org/10.5539/ies.v8n5p139

\begin{abstract}
The study deals with self-regulation in children and minors (aged 11 to 19 years) living in so-called "total institutions". It examines the degree of self-regulation of behaviour from the perspective of the children and minors themselves and from the perspective of their key workers. Children and minors and their key workers differ significantly in perception of the wards' self-regulation of behaviour in the short and long-term context. The lowest rate of self-regulation in children and minors in institutional care is reflected in the area of regulation of emotions. The results point to certain specificity of the institutional care environment.
\end{abstract}

Keywords: self-regulation, children and minors, institutional care, social environment, key workers

\section{Theoretical Background}

Contemporary society has been facing a number of issues that share a common denominator. Alcoholism, crime, drug addiction, educational underachievement, gambling, eating disorders, anger management issues, debt and bankruptcy are problems that affect the whole society even though they represent the failure of an individual. An individual who experiences problems in a certain area of life may realise the consequences of their own behaviour, however ultimately they lose control over their own lives, failing in the self-regulation of their behaviour (Baumeister \& Bushman, 2008).

Self-regulation refers to the capacity of the self to alter one's behaviour (Baumeister \& Vohs, 2007). Zimmerman (2005) states that self-regulation is directly connected with the goal of social acceptance. Self-regulation (as one of the intrapersonal skills) is the ability to flexibly activate, monitor, inhibit, persevere and/or adapt one's behaviour, attention, emotions and cognitive strategies in response to direction from internal cues, environmental stimuli and feedback from others, in an attempt to attain personally-relevant goals (Moilanen, 2007; Demetriou, 2005; Novak \& Clayton, 2001). This flexibility allows people to adjust to societal and situational demands that they encounter on a daily basis (Baumeister \& Vohs, 2007). Specifically, self-regulation places one's "social conscience" over selfish impulses, allowing people to do what is right and not what they want to do (Baumeister \& Bushman, 2008).

The ability to regulate one's own behaviour is dependent on the temporal context in which it takes place (Barkley, 1997; Moilanen, 2007). Temporal frames are crucial for a conflict to emerge between immediate benefits or future costs. Control or regulation of one's own behaviour and emotions in the immediate context in order to attain long-term goals requires special efforts which in conjunction with other preconditions (personal standards, willpower, motivation, strategies or monitoring) play a crucial role in the process of self-regulation.

When talking about regulation of self, i.e. an internal intention to change one's own behaviour, it is of primary importance to identify one's own intention. The change begins with identifying one's own expectation, i.e. a personal goal. These objectives, which are interpreted from the outside world, must first be individualised, i.e. converted into a structure of one's own possibilities, abilities, motives, needs and experiences. The ability to convert such external requirements into individual goals is a fundamental prerequisite for successful self-regulation. Another prerequisite of self-regulation is self-regulatory strength, or willpower. The process leading to the change of oneself is a difficult one and therefore it requires certain power. Due to our own will and determination, we are able to persevere and not give up when overcoming obstacles. The effort made for a specific activity, i.e. the change, is dependent on the experience/enjoyment of the activity. Highly enjoyable 
moments, the ones Csikszentmihalyi (1990) calls "flow experiences", make us feel completely absorbed in the activity alone so that we do not feel the need for any extra effort to perform the activity. This requires a certain kind of motivation. Without any internal human need for a change, the need to work on one's self-regulation cannot be achieved. Naturally, the sense of one's own autonomy brings greater responsibility for one's own actions.

The next step towards self-regulation is the choice of one's own strategy, i.e. processes that lead to the desired change in behaviour and are based on the set personal goals. Self-regulation is a cyclical process (Zimmerman, 2005), which requires self-reflection and systematic self-monitoring. We can say that it is the result of the interaction of one's own personality, with the social environment they live in and their own behaviour. Such an interaction is not immutable, it comes into existence and develops. Therefore it requires a person's ability to respond and adjust to these changes. Self-monitoring is a means to monitor one's own behaviour, to become aware of one's own limits, progress and results and it leads to the decision on one's further actions (e.g., considering help from the outside, etc.).

Self-regulation is a complex, multifaceted process, and therefore failure may occur. However, if we understand the causes of such failures occurring in the process of the self-regulation of one's behaviour, we may find out how to eliminate the causes and how to encourage the development of self-regulation of behaviour. According to the social-cognitive perspective (Zimmerman, 2005) the self-regulation skills develop gradually and in developmental levels. In the first phase self-regulation develops through observation. Although it is indirect information, it is important to be incorporated into behavioural strategies. This occurs more distinctly in the phase of emulation, in which imitative performance of a proficient model (the general pattern or style of function) occurs with social assistance. An independent display of the model manifests on the self-controlled level. The success in matching the standard during practice effort determines the amount of self-reinforcement. The self-regulated level is attained through systematic adaption of performance to changing personal and contextual conditions. This multilevel analysis of the development of self-regulation begins with the most extensive social guidance at the first level, while the social support is systematically reduced.

Self-determination theory distinguishes two types of self-regulated behaviour (Vansteenkiste et al., 2010): autonomous regulation (self-regulation) and controlled regulation (self-control). Autonomous regulation involves acting with a full sense of volition. This type of regulation is based on the internal needs of the individual. One of these needs is the need to preserve self-determination. Autonomous regulation is connected to the inner motivation of the individual. If a person is internally motivated, they seek such activities or goals, which are interesting, enjoyable and challenging. Internalised extrinsic motivation is also linked to autonomous regulation. The individual does not always act out of their inner need, but performs activities that are personally beneficial. Being autonomously extrinsically motivated requires that people identify with the value of behaviour for their own self-selected goals (Gagné \& Deci, 2005). In contrast, controlled regulation is connected to external motivation and introjected regulation. This type of regulation is characterised by feelings of internal or external pressure that conflicts with what one would otherwise choose (e.g., avoiding shame, interpersonal rejection, physical punishment, etc.).

Self-regulation refers to both, conscious and unconscious processes that affect the ability to control responses. It is a skill that affects the individual's ability to cope with adverse circumstances (manage failure, cope with disappointment, etc.) and its ability to transform one's skills needed for successful coping with life situations (work towards success). Self-regulation is often thought of as a dual process, cognitive and social-emotional (Blair \& Razza, 2007). Cognitive self-regulation is the degree to which people can be self-reflective, and can plan and think ahead. Individuals with these strengths are in control of their thoughts. They monitor their behaviour, evaluate their abilities, and are able to adjust their behaviour if necessary. Social-emotional self-regulation is the ability to inhibit negative responses and delay gratification. Individuals with these strengths are able to control their emotional reactions to positive and negative situations (Bandy \& Moore, 2010).

Sayette (2004) subdivides self-regulation failure as follows: underregulation and misregulation. Underregulation refers to a failure to control oneself whereas misregulation deals with having control in a manner that does not bring about the desired goal. Especially in an environment where children are vulnerable to risk behaviour (e.g., they do not live in the natural family environment, etc.) the process of self-regulated behaviour may not be automatic, although they may be aware of their problem behaviour (display self-knowledge). It is therefore very important to focus on preventing problem behaviour. Children living in total institutions may also belong in this group. The rehabilitative prognosis is rather pessimistic for most of these children due to the social environment they grew up in. We can frequently observe symptoms of institutionalisation in these groups of children and minors (Goffman, 2007). 


\section{Method}

The overall purpose of this study was to explore the degree of self-regulation in children and minors in institutional care. We wondered what sort of self-regulating processes appear in children and minors in the institutionalised environment and whether the children and minors living in this environment show deficits in certain processes of self-regulation of behaviour (affect, awareness, empowerment), and which timeframes of self-regulation prevail (the short or long term ones) in comparison with how their level of self-regulation is perceived by their social personnel (key workers) who are in everyday contact with the wards. Specifically, the following major research questions were created for the study.

- How do children and minors in institutional care perceive the degree of self-regulation of their own behaviour?

- What is the level of their awareness of deficits in certain processes of self-regulation, i.e. affect, awareness and empowerment?

- Which timeframes of self-regulation in children and minors in institutional care prevail (the short or long term ones)?

- Is the degree of self-regulation of behaviour in children and minors perceived as the same by the children themselves and by the key workers? Do key workers rate the degree of self-regulation of behaviour differently than children and minors themselves, than children of various age groups and gender orientation?

The Self-Regulation Questionnaire ( $S R Q$ ) was used for the purposes of the research. This questionnaire was adapted to the Czech environment (Hrbáčková \& Vávrová, 2014). It contains 12 items that measure the degree of self-regulation of children and minors (see Appendix) in three areas: Affect (\#5,\#6, \#8 a \#11), Awareness (\#3,\#7, $\# 9$ a \#10) and Empowerment (\#1,\#2, \#4 a \#12)in two temporal context: long-term (\#2,\#3, \#4, \#7, \#9, \#10 a \#12) and short-term( $\# 1, \# 5, \# 6, \# 8$ a \#11). All three dimensions explain $45.5 \%$ of the variance. The first factor (Affect) focuses on the experiences of feeling and emotion, and it represents the impulse to manage one's own behaviour. The second factor (Awareness) refers to the knowledge of self and strategies of regulation of one's own behaviour. The third factor (Empowerment) deals more directly with regulation of behaviour manifestations. The questionnaire covers the hierarchy of the processes of self-regulation of behaviour, ranging from regulation of emotions ("feeling"), knowledge of self and strategies of own behaviour ("knowing") to the actual control of one's own behaviour ("doing"). The confirmatory factor analysis provided evidence for a solid factor structure in different samples. The goodness-of-fit measures indicated a good fit for the model $\chi^{2}=(53)=78,835, \chi^{2}-$ fit $/ d f$ ratio $=1.487, \mathrm{CFI}=.905, \mathrm{RMSEA}=.069, \mathrm{SRMR}=.033, \mathrm{GFI}=.898, \mathrm{AGFI}=.850, \mathrm{PCLOSE}=.161$.

Participants responded to each item using a 5-point scale, ranging from 1 (False) to 5 (True). Items \# 5, \#6, \# 8 and \# 11 are reverse. In data processing, the answers in these items were re-coded. Key workers self-assessed behaviour of children and minors using the same questionnaire filled out by the children and minors.

The research pool consisted of children and minors $(n=102$ valid $)$ in institutional care (10 facilities of institutional care in the Czech Republic) aged 11-19 (mean age $=15$ years, $\mathrm{SD}=1.98$ ) and key workers who are in daily contact with the children. Table 1 presents the structure of the research group. Key workers evaluated a total of 95 children ( 7 responses were excluded due to incompleteness). Children and minors were divided into three age groups: children up to 15 years of age, minors $15-18$ years of age and young adults above 18 . The age division was based on the age of criminal liability. In terms of the current legislation of the Czech Republic, the criminal liability of minors displays some differences compared to adult criminal liability. A juvenile or a minor is a person who at the time of the commission of the offense has attained the age of 15 and has not exceeded 18 years of age. All the age groups of respondents (regardless of their age) will be referred to as children and minors. 
Table 1. Representation of respondents in research pool

\begin{tabular}{llll}
\hline Gender & Age (acc. to criminal responsibility) & $\mathrm{N}$ & $\%$ \\
\hline Boys & to 15 years (children) & 20 & 19.6 \\
& 15-8 years (minors) & 31 & 30.4 \\
& above 18 years (young adults) & 9 & 8.8 \\
Girls & to 15 years (children) & 15 & 14.7 \\
& 15-18 years (minors) & 22 & 21.6 \\
& above 18 years (young adults) & 5 & 4.9 \\
\hline Total & & 102 & 100 \\
\hline
\end{tabular}

The respondents filled out the questionnaires using the "paper - pencil" method. The data were processed through the SPSS programme version 21. One-Way ANOVA, t-test for independent and paired samples and Univariate Analysis of Variance (Two-Way ANOVA) were applied. We also tested the prerequisites for using the selected test, i.e. we verified the normality and homoscedasticity (Levene's test). The Cronbach's alpha coefficient for all 12 items reached .814, demonstrating a good internal consistency. All reliability coefficients were within an acceptable range with the exception of the Empowerment variable $\left(r_{c}=.526\right)$. This may have occurred because of the small number of items in the scale (4 items).

\section{Results}

The degree of self-regulation of behaviour is perceived (on a scale from 1 to 5) as average (see Table 2) by children and minors in institutional care. The values are slightly above 3 points $(\mathrm{M}=3.198, \mathrm{SD}=.688)$. The testimony of children and minors suggests that they feel the greatest deficit in the area of regulation of emotions (Affect). In this area, they reach the average values below 3 points $(\mathrm{M}=2.988, \mathrm{SD}=1.083)$. A more detailed analysis of individual items identifies their irritability as the biggest problem. On the other hand, it was revealed that they have no problem with calming themselves down when angry or improving their mood when sad. When things are not as they want them to be, they find it easier to figure out how to change them. The highest degree of self-regulation was detected in regulation of behaviour manifestation (Empowerment). The average value exceeds the threshold of 3 points $(\mathrm{M}=3.355, \mathrm{SD}=.849)$.

Table 2. Degree of self-regulation in children and minors in institutional care

\begin{tabular}{llll}
\hline Variable & Mean & Std. Deviation & Std. Error \\
\hline Affect & 2.988 & 1.083 & .107 \\
Awareness & 3.245 & .927 & .092 \\
Empowerment & 3.355 & .849 & .084 \\
Overall degree of self-regulation of behaviour & 3.196 & .688 & .068 \\
\hline
\end{tabular}

The perception of self-regulation of behaviour of children and minors in institutional care is similar in terms of time (see Table 3). The degree of self-regulation of behaviour related to the presence is slightly higher in children and minors in institutional care $(\mathrm{M}=3.204, \mathrm{SD}=.812)$ than self-regulation of behaviour from the long-term context $(\mathrm{M}=3.191, \mathrm{SD}=.713)$. However, these differences are not significant $(\mathrm{p}=.831)$. Respondents' ideas about regulating own behaviour in the longer term may be influenced by their perception of time. The answers indicate insignificant differences in the regulation of the present and future behaviour manifestations and thus show an active attitude of children and minors to regulation of behaviour that is directed to the future. According to them, they can equally regulate their present conduct, but also think about what they will do in the future, plan the process of their behaviour or strategy to deal with this situation. The question remains to what extent their statements correspond with reality (with the actual degree of self-regulation of behaviour) and how they can realistically predict their future behaviour. 
Table 3. Prevailing timeframes of self-regulation of behaviour in children and minors in institutional care

\begin{tabular}{llll}
\hline Variable & Mean & Std. Deviation & Std. Error \\
\hline Short-term & 3.204 & .812 & .080 \\
Long-term & 3.191 & .713 & .071 \\
\hline
\end{tabular}

When analysing the differences in the degree of self-regulation in children and minors of different ages in a certain time context, we found that children and minors regulate their behaviour in the short and long-term context to the same extent. However, the results show that the key workers assess the degree of self-regulation of the children's behaviour at different temporal context differently from the children and minors.

There are no differences in the long-term context among children and minors from the perspective of social personnel (see Table 4). However, in the short-term context young adults over 18 years of age lack in the degree of self-regulation of behaviour $(\mathrm{p}=.034)$.

Table 4. Prevailing timeframes of self-regulation of behaviour in children and minors acc. to key workers

\begin{tabular}{lllll}
\hline Timeframes & Age (acc. to criminal responsibility) & Mean & Std. Deviation & Std. Error \\
\hline Shor-term & to 15 years (children) & 2.720 & .778 & .142 \\
& $15-18$ years (minors) & $2.933 *$ & .781 & .109 \\
& above 18 years (young adults) & $2.286 *$ & 1.031 & .276 \\
Long-term & to 15 years (children) & 2.667 & .752 & .137 \\
& $15-18$ years (minors) & 2.912 & .927 & .130 \\
& above 18 years (young adults) & 2.357 & 1.045 & .279
\end{tabular}

Note. $*$ Difference is significant at the .05 level.

Within the next research phase, we decided to compare the perceived levels of self-regulation of behaviour in children and minors with how it is perceived by the key workers who are in daily contact with the wards (see Table 5).

In accordance with the children and minors themselves, the key workers also perceive the biggest problems in the area of self-regulation of emotions (Affect). The perceived degree of emotional self-regulation in children and minors from the perspective of the key personnel is below average $(\mathrm{M}=2.626, \mathrm{SD}=1.207)$. Key workers assess the manifestation of self-regulation of behaviour (Empowerment) the highest, but their perceived level falls below the threshold of 3 points $(\mathrm{M}=2.918, \mathrm{SD}=.856)$.

The responses show that the key workers assess the degree of self-regulation and all other processes of self-regulation of behaviour differently than the children and minors. The degree of self-regulation in the area of feelings and emotions (Affect) is significantly lower from the perspective of the social personnel than perceived by children and minors $(\mathrm{p}=.003)$. Similarly, awareness of self, knowledge of self and strategies that lead to control of one's own behaviour (Awareness) is seen as more problematic by the key workers than by the children and minors $(\mathrm{p}<.001)$. From the perspective of children and minors, manifestations of self-regulation (Empowerment) are represented in their behaviour to a greater extent than perceived by the key workers ( $\mathrm{p}$ $<.001)$. The largest differences in perception were detected in the area of Awareness (.51 point difference).

The degree of self-regulation of behaviour of children and minors is seen as rather below average by the key workers, while children perceive it as average. Both groups believe that the most problematic area is regulation of emotion, then knowledge of self and strategies for regulating behaviour and lastly manifestations of self-regulation of behaviour. The differences are obvious in the assessment of these processes. We may assume that the responses display a distinct shift in the perception of behaviour assessment. From the results, we may conclude that it is somewhat difficult to assess the degree of regulation of their own behaviour for children and minors. They are more likely to overestimate when deciding what behaviour is right from their perspective. Previous studies (Hladík \& Vávrová, 2011) show that these children and minors have a very precise notion of what is expected of them. 
Table 5. Differences in the perceived level of self-regulation of behaviour by children and minors in institutional care and by key workers

\begin{tabular}{lllll}
\hline Area of self-regulation & Evaluator & Mean & Std. Deviation & Std. Error \\
\hline \multirow{2}{*}{ Affect } & Children and minors & 3.021 & 1.081 & .111 \\
& Key workers & $2.626^{*}$ & 1.207 & .124 \\
Awareness & Children and minors & 3.247 & .943 & .097 \\
& Key workers & $2.742 * *$ & .864 & .089 \\
Empowerment & Children and minors & 3.379 & .843 & .087 \\
\multirow{2}{*}{ Overall degree of self-regulation of behaviour } & Key workers & $2.918 * *$ & .856 & .088 \\
& Children and minors & 3.216 & .680 & .070 \\
& Key workers & $2.762 * *$ & .835 & .086 \\
\hline
\end{tabular}

Note. $*$ Difference is significant at the .05 level. $* *$ Difference is significant at the .01 level.

Given that the age range of the sample is quite broad and the answers may not reflect the opinion of all children and minors from institutional care, we focused on differences in perception of the level of self-regulation of behaviour among children and minors. It can be assumed that the level of regulation of their behaviour may be perceived differently by minors who have reached the age of criminal responsibility, by children under 15 years of age or by young adults over 18 years of age.

The results show (see Table 6) that children and minors under 15 years of age, between 15-18 years and above 18 years of age perceive the degree of regulation of their behaviour in a similar way. The differences in self-regulation of behaviour regarding age are not significant $(\mathrm{p}=.636)$. The perceived degree of self-regulation does not differ significantly in the individual processes of self-regulation of behaviour (Affect, Awareness, Empowerment).

Table 6. Differences in the perceived level of self-regulation of behaviour of children and minors of different ages

\begin{tabular}{lllll}
\hline Area of self-regulation & Age group & Mean & Std. Deviation & Std. Error \\
\hline \multirow{3}{*}{ Affect } & to 15 years & 3.207 & 1.006 & .170 \\
& $15-18$ years & 2.939 & 1.107 & .152 \\
& above 18 years & 2.626 & 1.134 & .303 \\
Awareness & to 15 years & 3.414 & .868 & .147 \\
& $15-18$ years & 3.198 & .901 & .124 \\
Empowerment & above 18 years & 3.000 & 1.148 & .307 \\
& to 15 years & 3.186 & .751 & .127 \\
& $15-18$ years & 3.410 & .861 & .118 \\
Overall degree of self-regulation of behaviour & above 18 years & 3.571 & 1.012 & .270 \\
& to 15 years & 3.269 & .630 & .106 \\
& above 18 years & 3.182 & .671 & .092 \\
\hline
\end{tabular}

Key workers perceive the degree of self-regulation of behaviour of children and minors in different age groups differently (see Table 7). According to them, the highest degree of self-regulation of behaviour occurs in the age group of minors aged 15-18 years and the lowest one in the age group of young adults over 18 years of age. These differences in the perception of the degree of self-regulation of behaviour are significant in the overall level of self-regulation of behaviour $(\mathrm{p}=.049)$, in the area of awareness of self and knowledge strategies (Awareness), which lead to control/regulation of one's own behaviour $(\mathrm{p}=.035)$ and in the area of 
self-regulation of behaviour manifestations (Empowerment) $(\mathrm{p}=.009)$. In the area of regulation of emotions (Affect), the degree of self-regulation is similar $(\mathrm{p}=.500)$ in all age groups according to the key workers.

The low levels of self-regulation of behaviour in young adults (over 18 years) from the perspective of social personnel (compared with a group of minors aged 15 to 18) points out the specificity of this age group. Hence one of the reasons for prolongation of institutional care may be problematic behaviour of the young adults.

Table 7. Differences in the perceived level of self-regulation of behaviour in various age groups acc. to key workers

\begin{tabular}{lllll}
\hline Area of self-regulation & Age group & Mean & Std. Deviation & Std. Error \\
\hline \multirow{3}{*}{ Affect } & to 15 years & 2.650 & 1.074 & .196 \\
& $15-18$ years & 2.706 & 1.297 & .182 \\
& above 18 years & 2.286 & 1.160 & .310 \\
Awareness & to 15 years & 2.641 & .811 & .148 \\
& $15-18$ years & $2.927 *$ & .825 & .116 \\
& above 18 years & $2.286 *$ & .965 & .258 \\
Empowerment & to 15 years & 2.775 & .844 & .154 \\
& $15-18$ years & $3.142 *$ & .716 & .100 \\
& above 18 years & $2.411 *$ & 1.103 & .295 \\
Overall degree of self-regulation of behaviour & to 15 years & 2.689 & .735 & .134 \\
& $15-18$ years & $2.925 *$ & .813 & .114 \\
& above 18 years & $2.328 *$ & .984 & .263 \\
\hline
\end{tabular}

Note. $*$ Difference is significant at the .05 level.

It was found out that the key workers assess the degree of self-regulation of behaviour differently compared to the children and minors themselves (regardless of their age). At the same time, we also found that children and minors evaluate the degree of self-regulation of their behaviour similarly in all age groups, however the key workers believe that the rate of self-regulation of behaviour in different age groups changes. Therefore we wanted to see if the degree of self-regulation of behaviour manifests itself differently in children (under 15 years), in minors (aged 15-18 years) and in young adults (over 18 years) depending on whether it is considered by the key workers or the children and minors themselves. Also whether the interaction of both factors (in case it is evaluated by the children and minors themselves or by the key workers) influences the degree of self-regulation of behaviour. 


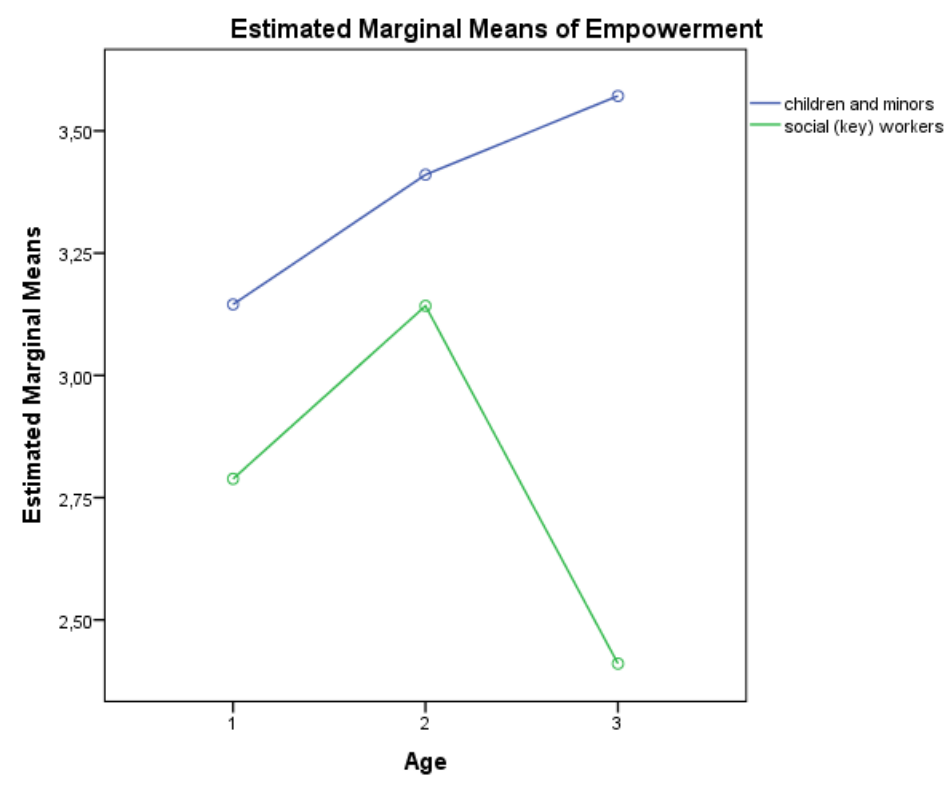

Figure 1. Main effects of interaction model of manifestations of self-regulation of behaviour in children and minors

The results show that joint influence of the two factors is significant only in the area of Empowerment. The analysis shows that manifestations of self-regulation of behaviour (Empowerment) are perceived differently in different age groups depending on who assesses them (see Figure 1). The joint effect of the two factors proved to be significant $(\mathrm{p}=.046)$. The analysed model explains $11.6 \%$ of the variability of the degree of self-regulation of behaviour $\left(\mathrm{R}^{2}=.116\right)$. The largest differences in assessment of the degree of self-regulation of behaviour by the key workers and children themselves are visible in the age group of young adults over 18 years of age.

The degree of self-regulation of behaviour was assessed by both, boys and girls from institutional care similarly $(\mathrm{p}=.756)$ (see Table 8). Gender differences are not apparent in individual processes of self-regulation (Affect, Awareness, Empowerment). Girls rated regulation of their own emotions as the most problematic $(\mathrm{M}=3.024$, SD $=1.139)$, as well as boys, who assess the level of emotion regulation below 3 points $(\mathrm{M}=2.962, \mathrm{SD}=1.051)$. The boys evaluate manifestations of regulation of their own behaviour as above average $(\mathrm{M}=3.413, \mathrm{SD}=.855)$, the girls agree that this area of self-regulation is the least difficult one $(\mathrm{M}=3.273, \mathrm{SD}=.844)$.

Table 8. Gender differences in the perceived level of self-regulation of behaviour of children and minors

\begin{tabular}{lcccc}
\hline Area of self-regulation & Gender & Mean & Std. Deviation & Std. Error \\
\hline \multirow{2}{*}{ Affect } & boys & 2.962 & 1.051 & .136 \\
& girls & 3.024 & 1.139 & .176 \\
Awareness & boys & 3.267 & .991 & .128 \\
\multirow{2}{*}{ Empowerment } & girls & 3.214 & .838 & .129 \\
& boys & 3.413 & .855 & .110 \\
Overall degree of self-regulation of behaviour & girls & 3.273 & .844 & .130 \\
& girls & 3.171 & .677 & .090 \\
\hline
\end{tabular}

The key workers do not report any significant differences in the degree of self-regulation of behaviour in girls and boys from institutional care. They see the degree of self-regulation in girls and boys as similar $(p=.663)$. We wondered, therefore, if the rate of self-regulation manifests itself differently in boys when viewed by key workers or by the children and minors themselves. Also if it manifests itself differently in girls when viewed by 
key workers or by the children and minors themselves. We also wondered whether the degree of self-regulation of behaviour of children and minors is influenced by active interaction of both factors (in case it is assessed by the children and minors themselves or by key workers and when boys or girls are being assessed).

The joint effect of the two factors emerged as significant in the overall degree of self-regulation and in individual processes of self-regulation. The differences in the degree of self-regulation is caused by one of the factors examined, i.e. the person who assesses the degree. Key workers assess the degree of self-regulation and individual processes of self-regulation differently than the children and minors themselves, regardless of whether they are boys or girls. We believe that in the research sample of children and minors in institutional care the degree of self-regulation of behaviour is often associated with problem behaviour, which does not necessarily relate to the gender of these children and minors living in institutional environment. Such differences are more likely to appear in the general population of children and youth.

\section{Discussion and Conclusion}

The results show that children and minors in institutional care assess the degree of self-regulation of their behaviour as average ( $\mathrm{M}=3,198$ points). They do not think that they are able to regulate own behaviour fully, but at the same time they do not feel a significant deficit in this area.

According to the participating children and minors, they can equally regulate their present conduct, as well as think about their future actions, i.e. to plan the process of their behaviour or strategy to deal with certain situations. The degree of self-regulation of behaviour in the short and long-term context is comparable and it is not age-dependent based on the participants' responses. Children and minors regulate their behaviour to the same extent in the short and long-term context. However, the key workers believe that there are differences in the self-regulation of behaviour particularly in the short-term context. According to them, young adults over 18 years lack in degree of self-regulation of behaviour (in the short-term context) $(\mathrm{p}=.034)$, which is inconsistent with the theory of Barkley (1997) which claims that young adults are able to plan or prepare for events that are both near and distant in time, while children are limited to events that are temporally near. Differences in the degree of self-regulation of behaviour should thus be more pronounced in the long-term context. It could be assumed that children regulate their own behaviour directed to the future to a lesser extent than minors and young adults. It is also possible that the temporal context does not play an important role in the case of children and minors in institutional care as their level of self-regulation may be related to the environment of institutional care and to their problem behaviour or it rather reveals more about what is expected of them.

Children and minors consider regulation of their own emotions (Affect) to be their greatest deficit. In a more detailed analysis of individual items, they reported that the greatest problem to them is their irritability, i.e. getting upset easily. On the other hand, they revealed that they do not find it difficult to calm themselves down when angry or to improve their mood when sad. If things are not as they would like them to be, then, according to them, it is easier to cope and to change them. The highest degree of self-regulation was identified in the manifestations of regulation of their own behaviour (Empowerment).

We found out that the degree of self-regulation of behaviour in children and minors is evaluated differently by their key workers and by the children and minors themselves. According to the key workers, children and minors reach lower levels of self-regulation of behaviour than the children and minors reported themselves. Both groups, however, agree that the most problematic area is regulation of emotions (Affect), then knowledge of self and strategies to regulate one's own behaviour (Awareness) and lastly, manifestations of self-regulation of behaviour (Empowerment).

Children and minors of different ages (up to15 years, 15 to 18 years and above 18 years) assess the degree of self-regulation of their behaviour on the same level, i.e. the degree of self-regulation of behaviour is the same in all age categories. According to the key workers, the highest degree of self-regulation is achieved in minors (15 to 18 years) compared to young adults (over 18 years) who scored the lowest levels. Such low levels of self-regulation of behaviour in young adults (over 18 years) from the perspective of social personnel (compared with a group of minors aged 15 to 18) points out the specificity of this age group. Possible prolongation of institutional care may therefore be the result of problematic behaviour of these young adults. We can indirectly assume that low degree of self-regulation is to be associated with manifestations of risk (problem) behaviour of young adults.

The joint effect of both factors and their interaction is significant only in the area of manifestations of self-regulation of behaviour (Empowerment). In this area, the degree of self-regulation of behaviour is assessed differently by the key workers and by the children and minors themselves depending on the age of the assessed children and minors. The joint effect of the two factors emerged as significant $(p=.046)$. The analysed model 
explains $11.6 \%$ variability of the degree of self-regulation of behaviour $\left(\mathrm{R}^{2}=.116\right)$. The most prominent differences in the evaluation of manifestations of self-regulation of behaviour by key workers and by children and minors themselves is seen in the age group of young adults over 18 years of age.

Children and minors also reported that the level of self-regulation of behaviour in girls and boys is the same. Similarly, the key workers agree that there is no significant difference in the degree of self-regulation of behaviour between boys and girls. We believe that the differences would be more pronounced in children and minors living in the natural environment as the institutional environment is very specific in its nature. Children and minors living in long-term total institutional care may in older age show certain deviations from the norm in terms of personality development and their social applications (Matějček, Bubleová, \& Kovařík, 1996). Risk behaviour tends to occur more in institutional care than in the natural environment. The differences in the degree of self-regulation of behaviour in children and minors in institutional environment may be affected by these risk factors rather than gender differences or criminal liability of children and minors.

We wish to focus our further research on comparing self-regulation of behaviour of children and minors in natural and institutional environments and thus verify the connection between the degrees of self-regulation of behaviour with risk behaviour manifestations. The results show a rather lower level of self-regulation of behaviour (especially emotion regulation) in children and minors in institutional care, particularly from the perspective of the social personnel. The study also shows the problematic nature of measuring self-regulation of behaviour by the children and minors themselves. We believe that in the natural environment, the development of self-regulation skills (learning) is a natural part of the interaction with parents and peers. In institutional care such a development is limited by several factors (mainly the lack of parental care, i.e. parents would pass on the patterns of behaviour in a natural way). We therefore consider it necessary to encourage the development of self-regulation of behaviour in children and minors in institutional care, to work with these children and provide them with maximum support so that they are able to regulate their behaviour and in particular their emotions, so that they become aware of the consequences of their actions and strategies that lead to successful regulation of their own behaviour.

\section{Acknowledgements}

This study was published with support of the Czech Science Foundation GA ČR 13-04121S Understanding the Mechanism of Self-Regulation in Children and Minors in Institutional Care.

\section{References}

Bandy, T., \& Moore, K. A. (2010). What Works for Promoting and Reinforcing Positive Social Skills: Lessons from Experimental Evaluations of Programs and Interventions. Washington, DC: Child Trends.

Barkley, R. A. (1997). Behavioral Inhibition, Sustained Attention, and Executive Functions: Constructing a unifying theory of ADHD. Psychological Bulletin, 121, 65-94. http://dx.doi.org/10.1037//0033-2909.121.1.65

Baumeister, R. F., \& Bushman, B. J. (2008). Social Psychology and Human Nature. San Francisco: Wadsworth.

Baumeister, R. F., \& Vohs, K. D. (2007). Self-Regulation, Ego Depletion, and Motivation. Social and Personality Psychology Compass, 1, 1-14. http://dx.doi.org/10.1111/j.1751-9004.2007.00001.x

Blair, C., \& Razza, R. P. (2007). Relating Effortful Control, Executive Function, and False Belief Understanding to Emerging Math and Literacy Ability in Kindergarten. Child Development, 78(2), 647-663. http://dx.doi.org/10.1111/j.1467-8624.2007.01019.x

Csikszentmihalyi, M. (1990). Flow: The Psychology of Optimal Experience. Harper and Row: New York.

Demetriou, A. (2005). Organization and Development of Self-Understanding and Self-Regulation: Toward a general theory. In M. Boekaerts, P. R. Pintrich, \& M. Zeidner (Eds.), Handbook of Self-Regulation (pp. 209-251). San Diego: Academic Press. http://dx.doi.org/10.1016/B978-012109890-2/50036-6

Gagné, M., \& Deci, E. L. (2005). Self-Determination Theory and Work Motivation. Journal of Organizational Behavior, 26, 331-362. http://dx.doi.org/10.1002/job.322

Goffman, E. (2007). Asylums: Essays on the Social Situation of Mental Patients and Other Inmates. New Brunswick: Transaction Publishers.

Hladík, J., \& Vávrová, S. (2011). Mechanismy fungování rozvoje autoregulace učení studentů. Praha: Hnutí R, 2011.

Hrbáčková, K., \& Vávrová, S. (2014). The Development and Validation of the Self-Regulation Questionnaire in 
Children and Minors. Procedia-Social and Behavioral Sciences, 112, 730-737. http://dx.doi.org/10.1016/j.sbspro.2014.01.1224

Matějček, Z., Bubleová, V., \& Kovařík, J. (1996). Pozdní následky psychické deprivace a subdeprivace. Československá psychologie, 20(1), 14-27.

Moilanen, K. L. (2007). The Adolescent Self-Regulatory Inventory: The development and validation of a questionnaire of short-term and long-term self-regulation. Journal of Youth and Adolescence, 36, 835-848. http://dx.doi.org/10.1007/s10964-006-9107-9

Novak, S. P., \& Clayton, R. R. (2001). The Influence of School Environment and Self-Regulation on Transitions between Stages of Cigarette Smoking: A multilevel analysis. Health Psychology, 20, 196-207. http://dx.doi.org/10.1037//0278-6133.20.3.196

Sayette, M. A. (2004). Self-regulatory Failure and Addiction. In R. F. Baumeister, \& K. D. Vohs (Eds.), Handbook of Self-regulation: Research, Theory, and Applications (pp. 448-466). New York: Guilford Press.

Vansteenkiste, M., Smeets, S., Soenens, B., Lens, W., Matos, L., \& Deci, E. L. (2010). Autonomous and Controlled Regulation of Performance-Approach Goals: Their relations to perfectionism and educational outcomes. Motivation and Emotion, 34, 333-353. http://dx.doi.org/10.1007/s11031-010-9188-3

Zimmerman, B. J. (2005). Attaining Self-Regulation: A Social Cognitive Perspective. In M. Boekaerts, P. R. Pintrich, \& M. Zeidner (Eds.), Handbook of Self-Regulation (pp 13-29). San Diego: Academic Press. http://dx.doi.org/10.1016/B978-012109890-2/50031-7

\section{Appendix}

Factor loading of The Self-Regulation Questionnaire (SRQ)

\begin{tabular}{|c|c|c|c|c|}
\hline \multirow[b]{2}{*}{ No. } & \multirow[b]{2}{*}{ Item } & \multicolumn{3}{|c|}{ Factor } \\
\hline & & 1 & 2 & 3 \\
\hline 6 & I get upset by little things. & .813 & & \\
\hline 8 & I get offended easily. & .809 & & \\
\hline 5 & I get upset easily. & .691 & & \\
\hline 11 & I get upset every time things are not my way. & .678 & & \\
\hline 7 & I can cope even when things are not as I want them to be. & & .715 & \\
\hline 9 & If I want something, I can be impatient. & & 612 & \\
\hline 3 & I think before I act. & & .584 & \\
\hline 10 & If I want something I usually plan ahead how to get it. & & .538 & \\
\hline 4 & $\begin{array}{l}\text { If things are not the way I want them to be, I try to do } \\
\text { something about it. }\end{array}$ & & & .704 \\
\hline 1 & I can hide my feelings. & & & .607 \\
\hline 2 & I can cheer myself up when sad. & & & .583 \\
\hline 12 & I can calm down when upset/angry. & & & .546 \\
\hline Eigenvalue & & 3.932 & 1.934 & 1.406 \\
\hline
\end{tabular}

\section{Copyrights}

Copyright for this article is retained by the author(s), with first publication rights granted to the journal.

This is an open-access article distributed under the terms and conditions of the Creative Commons Attribution license (http://creativecommons.org/licenses/by/3.0/). 